\title{
The root causes of China's, Europe's and the United States' produced sports performance characteristics
}

\author{
Cao Xue \\ (Xiangyang Vocational and Technical College Department of Basic Courses;xiangyang 441050)
}

Keywords: Chinese traditional athletics; European and American sports; Performance characteristic; Source

Abstract. In this paper, literature review and research methods of theoretical analysis of the root causes of China, Europe and the United States Sports features and performance characteristics produced were analyzed and described, concluded that cultural differences between China, Europe and the United States of regional differences, political , military background and health differences are the main source of two kinds of sports performance characteristics of different produce.

\section{Introduction}

Today mankind has entered a "globalization" era, the rapid development of the transport network, information, national economies are highly dependent on such cultural exchanges and permeate all parts of society more widely and deeply. People are increasingly aware of the "peace and development" is the theme of the times, various nationalities different religions, different behaviors of values coexist. This environment of the international community to open up people's vision, inspire people's ideas, people more aware of the limitations of their own culture and other cultures can learn from nature. Sport as a form of cultural and socio-cultural act of human society, there are bound to different geographical and cultural imprint, different nationalities. The East (mainly China) West (primarily Greece) Sports Culture on social development and changes of the historical background to discuss their differences, helps us to understand the development trend of sports and culture from a sociological perspective.

\section{2 root cause of the performance characteristics of different produce}

There are differences in the performance of human health and the natural unity and unified force God, row minor movement in conjunction with the pursuit of quality focus function, overall coordination of yin and yang balance and stressed that the central section highlights other aspects of China, Europe and the United States sports performance characteristics. Different performance characteristics have their different root causes.

\section{1 cultural differences}

National culture is always manifested in a certain form, and other cultural phenomena, must also sports with a certain cultural identity, but also more and more intuitive, image more vivid. Chinese traditional culture due to the influence of Confucian philosophy, refracted in the sports highlight will form the traditional sports culture idea; Chinese traditional culture emphasizes the group is based, ethics as the center; emphasis on the Chinese people's traditional values integrity , harmony and unity, and the exclusion of the pursuit of innovation, the results tend to make people afraid to venture Situation comfortable, Anpinyuedao contentment Changle. This reflects the deep national consciousness in sports is: just entertainment, not for the outcome; just cultivation, does not seek to create; just skills, not for adventure; just elegant, not for the sublime. Chinese long cultural tradition, formed a unique martial arts, qigong as the mainstay of Chinese traditional sports. It is built on the philosophy based on the ancient Chinese natural, dynamic method and the resulting understanding of the overall concept of intuition and insight.

Influence of Religious Culture on Europe Sports: Ancient Greece with Athens secularization , personified democracy fostered by advocating personal indulgence, mature enjoy Dionysian culture, the development of ancient Greek entertainment, unique aesthetic body awareness, and individual the principle of personality and fashion conscious sports starting formation. West, theocratic medieval override royalty, religion and church overarching social ideology of religion under the 
control of human nature in the religious repression disappear theocracy, the secular human values was denied a fundamental, competitive sports was wiped out, and Modern Times Renaissance promoted the Reformation movement, confirmed the "Body and Soul unity" relationship, thereby clearing the mental barriers sports development, establishes the principle of comprehensive physical and mental development, equality and fraternity, thought opened the way to the door to universal education .

\subsection{Regional Differences}

Geographical conditions for the generation of two different characteristics of sports China, Europe and the United States possible.

From the geographical point of view: China is located in East Asia, Southeast vast sea, southwest of the majestic Himalayas, northwest vast desert. In this particular geographical conditions, the ancient Chinese people's hard to imagine beyond the vast Shenzhou earth can someone smoke is present. Yellow fertile soil to nourish her children, mild climate soothe her sons, splendid culture of the Yellow River tending her subjects. People by day labor, dependent on the weather, so as to cultivate a grateful dependence and worship 、 natural faith, so nature has become the most primitive totem of the Chinese nation.

The birthplace of Western civilization in Greece, the Greek peninsula located in mountainous terrain, climate variability, inadequate rainfall, these natural conditions determine the Greeks can not rely on agricultural production, and is mainly engaged in handicrafts - commercial and seafaring. They can not rely on the weather, worship of nature not as pious as the Chinese ancestors. On the contrary, and do not depend on a small commune full advantage of the capabilities of each member, for their own survival and independence struggle wealthy. In sailing, people will have to fight with the wind waves, as their means of livelihood, which created a spirit world of the Greeks is to encourage people to explore the unknown - brave and enterprising, the development of human potential and physical ability. They chose vibrant 、 full of pioneering way of life, and develop into different national character, and then elevated to a different culture. Correspondingly, sports and health thinking in ancient Greece, they seek outside, emphasizing body movement, through physical exercise to build muscle, strengthen the constitution, in order to achieve health objectives.

\subsection{Political and Military Background}

Chinese ancient politics is "totalitarian autocracy", as early as the Shang period gave rise to this "political centralization", one of its characteristics is to have a strong clan kinship mechanisms and regulations, obvious patriarchal mean, after this political background that ownership is the patriarch of ownership, society can not be real freedom and equality, the rule of the Shang Dynasty in the region, all the land and all the people belong to the Shang kings in name. Autocratic behind this patriarchal system and the hierarchy at work. Since the mechanism patriarchal and hierarchical mechanisms overemphasized, and can not produce any significant effect, because the hierarchy is to ask people psychologically consciously and unconsciously obey the statue under humble, patriarchal system can not determine the existence of fair competition. Sports culture is a must in a fair competitive basis, as long as fair competition, contestants must be exactly equal to the requirements in terms of identity,status, etc., and there is nothing under the humble respect of the points, this is absolutely outrageous in China. Chinese feudal society "folk sports" often suppressed because of the huge imperial power, and can not be subject to overall business culture baptism, can not become conscious of the kind of ancient Greek sport. But only a small range of small-scale , ow levels of physical activity has generated a number of antagonistic identity between the same crowd, its main feature is to produce a closed, non-confrontational manner with the movement of juggling skills .

Ancient Greece Slavery democratic political system for the economic and cultural development and prosperity of ancient Greek history have provided decisive support, but also for the birth of Greek sport to flourish and laid a sports event invaluable social conditions. Games began in 776 BC, this period is just the Greek primitive clan society collapse, the gradual formation of the historical period of slavery in this historical period, in Greece only thirteen million square kilometers of land, 
the establishment of more than two hundred a city-state, and where the vessel at the time and place to be, almost all the rise of colonists Greek cities, which the city has since become independent of government, separated from each other to form a unified and independent of both political and social structures. Ancient Greek has not been established as countries with similar Oriental unified, but many of the city are nothing but a common belief in God, speak the same language, and with equal status and power to participate in various activities, which provide the basic conditions to produce the Olympic Games . Ancient Greek society no despotism and autocratic monarchy, which are clearly reflected in Greek mythology. That Greek mythology God and people live in a secular environment smell, rather than as full of oriental myth too strong patriarchal meaning.

\subsection{Health}

Chinese traditional sports and medicine are the formation and development under the same conditions in our country's history, they complement each other, learn from each other, mutual penetration. From the ancient "Three medicine" to the Han Dynasty "Yellow Emperor" established in the medical knowledge of human physiology, pathology and disease prevention, the basic theory of medical treatment, but also established a foundation of traditional Chinese medicine Sports. In Chinese medicine, "the whole concept of" the impact of China attaches great importance to traditional sports body's own unity and harmonious relationship with nature. On the training methods, whether qigong, martial arts or other traditional sports attach great importance to comprehensive regulation of total body condition. Qigong martial arts are particular about: "Vivid, internal and external integration," qigong "tone the body, aligning, adjusting interest rates," the three elements is the "overall concept" a typical example. But this "holistic view" is not built on the basis of the understanding of the human body on science intensive, but have some experience, intuition, vague nature, even with a somewhat mysterious. This makes it difficult to follow their own inherent direction to a more scientific level.

Europe and the west of the sports medicine as the theoretical basis, and with the development of natural science and development. The theory is based on scientific experiments, anatomy, physiology, modern medicine, biology, etc. on top, so that sports an integrated application of these disciplines. Italian doctor $\mathrm{Hz}$ - US Mei'erkuliyalisi 1569 published "On the gymnastics" is the study of sport in modern experimental science from the perspective of the earliest and most influential work; and "German as early as the end of the eighteenth century and had applied mathematics knowledge of physics to analyze the technical principles of the movement, the creation of the Swedish gymnastics, is based on the physiological, anatomical and medical law, and therefore more scientific, more vitality, and so on. " One important reason for this is that European and American sports in the nineteenth century, began to spread to China, quickly occupied a dominant position.

\section{Conclusion}

3.1 "in harmony with nature, nature and man", "Form and Spirit, raising, combination of movement", " overall coordination of yin and yang balance" is the performance characteristics of Chinese traditional sports, traditional sports of Western forces are mainly focused on speed, sensitive and Quality improvement, the pursuit of strong bones,muscle ligaments and other functions to improve the appearance and make able-bodied.

3.2 Regional Differences Cultural Differences,military background and differences in political health of China, Europe and the United States is the main source of two kinds of sports performance characteristics of different produce.

3.3Two PE China, Europe and the United States is the world's cultural treasures, but also the common wealth of the whole human society. We should actively develop and use of these social resources for the future, to better benefit of mankind. Therefore, the current we should vigorously carry forward the spirit of traditional Chinese sports, work hard to develop, coordinate complementary work in harmony with Western sports and fitness, making common shoulder the historical responsibility to improve the quality of the entire nation. 


\section{References:}

[1] Zhou xikuan.Sports History [M] Beijing: People's Sports Publishing House .1990.

[2] Zeng Qingzong. On the similarities and differences between China, Europe and the United States sports [J]. Physical Education and Science. 1998 (5).

[3] Duan Guimei, Liu Dingyi. Again on the comparison of Chinese and Western Sports of Anhui Sports Science. 1994 (1).

[4]Liang Jing.Western Traditional Cultures comparison [J]. Tianjin Institute of Physical Education, 1989 (4).

[5] Lu Yuanzhen. Chinese sports sociology [M] Beijing: Beijing Sports University Press, 1996.

[6] Liao Xiaohua. Analysis of Chinese Traditional Concept of Physical Fitness Thinking and Europe Xinjiang Education Institute .2004,20 (2).

About the author: CAO Xue, male, in November 1977, Hubei Xiangfan, Xiangyang Vocational and Technical College Department of Basic Courses, Research Interests: Physical Education and Training Mailing Address: Hubei Xiangyang Vocational and Technical College of Public Courses, Zip code: 441050 E-mail: 564985046@qq.com 